\title{
CAMINHOS TRILHADOS E PERSPECTIVAS PARA A FORMAÇÃO DO PROFESSOR COMO INTELECTUAL TRANSFORMADOR
}

\author{
Trailed tracks and perspectives for training the teacher as an intellectual transformer
}

Caminos trilados y perspectivas para la formación del profesor como intelectual

transformador

Wélica Patrícia Souza de Freitas ${ }^{1}$

Vivian dos Santos Calixto ${ }^{2}$

\begin{abstract}
Resumo
O presente texto objetiva, por meio da exposição e problematização de uma narrativa acerca do processo de constituir-se professora, apresentar possibilidades de discussão da pedagogia crítica, mais especificamente do modelo formativo do professor como Intelectual Crítico Transformador desenvolvido por Giroux. Para tanto organizamos este percurso narrativo por meio de quatro movimentos, dos quais pode-se destacar: Primeiros passos: encontro com a perspectiva CiênciaTecnologia-Sociedade (CTS); O despertar crítico; Imersão em sala de aula: dificuldades emergentes e perspectivas, e; A busca por um continuum formativo. Argumentamos sobre a potencialidade da pedagogia crítica como arcabouço teórico para que o professor possa atuar de forma a ser um agente atuante na luta por uma sociedade mais justa e igualitária, bem como na sua emancipação e autonomia, obtida a partir de uma análise crítica das ações pedagógicas.
\end{abstract}

PALAVRAS-CHAVE: pedagogia crítica, autonomia profissional, formação de professores.

\begin{abstract}
The present text aims to present possibilities of discussion of critical pedagogy, more specifically of the teacher training model as Transforming Intellectual Transformant developed by Giroux, through the exposition and problematization of a narrative about the process of becoming a teacher. For this, we organize this narrative course through four movements, of which we can highlight: First steps: encounter with the Science-Technology-Society (CTS) perspective; The critical awakening; Immersion in the classroom: emerging difficulties and perspectives, and; The search for a formative continuum. We argue on the potentiality of critical pedagogy as a theoretical framework so that the teacher can act in order to be an active agent in the struggle for a more just and egalitarian society, as well as in its emancipation and autonomy, obtained from a critical analysis of the actions pedagogical.
\end{abstract}

KEYWORDS: Critical pedagogy. Professional autonomy. Teacher training.

\section{Resumen}

\footnotetext{
${ }^{1}$ Professora da Rede Estadual do Mato Grosso do Sul. Licenciada e Bacharel em Química. Endereço: Cidade Universitária, Caixa Postal 549. CEP 79070-900. Campo Grande - MS. Telefone: 67-99929-3405. E-mail: welicapsf@gmail.com

${ }^{2}$ Professora Assistente de Ensino de Química - Universidade Federal da Grande Dourados. Mestre em Educação em Ciências pela Universidade Federal do Rio Grande (FURG). Endereço: Rodovia Dourados - Itahum, Km 12, Caixa Postal - 533 - CEP: 79804-970 - Dourados/MS. Telefone: 67-999551888. E-mail: viviancalixto89@gmail.com
} 
El presente texto objetiva, por medio de la exposición y problematización de una narrativa acerca del proceso de constituirse profesora, presentar posibilidades de discusión de la pedagogía crítica, mas específicamente del modelo formativo del profesor como Intelectual Crítico Transformador desarrollado por Giroux. Para ello organizamos este recorrido narrativo por medio de cuatro movimientos, de los cuales se puede destacar: Primeros pasos: encuentro con la perspectiva CienciaTecnología-Sociedad (CTS); El despertar crítico; Inmersión en el aula: dificultades emergentes y perspectivas, y; La búsqueda de un continuum formativo. Argumentamos sobre la potencialidad de la pedagogía crítica como marco teórico para que el profesor pueda actuar de forma a ser un agente actuante en la lucha por una sociedad má justa e igualitaria, así como en su emancipación y autonomía, obtenida a partir de un análisis crítico de las acciones pedagógicas.

PALABRAS CLAVE: Pedagogía crítica. Autonomía professional. Formación de profesores

\section{INTRODUÇÃO}

Apresentaremos neste artigo, o relato da trajetória formativa de uma professora de Química, desde a graduação, imersão em sala de aula e a descoberta pelo desejo em lapidar-se objetivando uma aproximação com o modelo formativo do professor como Intelectual Crítico Transformador, apresentado por Giroux (1997). Modelo que se fundamenta numa perspectiva progressista de educação, pautada numa pedagogia crítica, a qual possibilita ao professor estabelecer uma visão crítica do contexto no qual está inserido analisando suas condições sociais, econômicas, políticas, objetivando superar a alienação para a construção de sua autonomia profissional.

Este artigo está organizado a partir de quatro momentos, no primeiro o qual intitulamos: "Primeiros passos: encontro com a perspectiva Ciência-Tecnologia-Sociedade (CTS)", apresentaremos o início da construção do "ser professora", fato constituído ainda na graduação, a partir da leitura de artigos pautados na abordagem CTS. O segundo momento denominado, "O despertar crítico" baseia-se no relato do encontro com a pedagogia crítica de Henry Giroux, mais especificamente, o modelo Formativo de professores como Intelectuais Críticos Transformadores, e suas aproximações com a prática pedagógica desenvolvida pela professora em seu Trabalho de Conclusão de Curso.

No terceiro momento, "Imersão em sala de aula: dificuldades emergentes $e$ perspectivas" discutiremos alguns obstáculos encontrados após a imersão no contexto escolar, na atuação como professora de escola pública e desenvolvimento de práticas orientadas pela perspectiva CTS. No quarto e último momento, intitulado "A busca por um continuum formativo", apresentamos os anseios na busca pela formação como Intelectual Crítico, objetivando possibilitar aos estudantes um Ensino de Química, pautado em uma perspectiva progressista, que transcenda os muros da escola a partir de uma educação crítica e igualitária.

\section{Primeiros passos: encontro com a perspectiva Ciência - Tecnologia - Sociedade (CTS)}

Ingressei no curso de Licenciatura e Bacharelado em Química na Universidade Federal da Grande Dourados (UFGD) em 2011, com o objetivo de atuar na área de pesquisa em Química Inorgânica. Porém, o primeiro contato com o componente curricular de Prática de Ensino de Química propiciou-me vislumbrar várias possibilidades em ensinar o componente de Química no Ensino Básico. Fato instigado a partir da leitura e discussão do 
artigo de Santos e Mortimer (2002) intitulado "Uma análise de pressupostos teóricos da abordagem C-T-S (Ciência - Tecnologia - Sociedade) no contexto da educação brasileira". A partir do qual pude notar as várias possibilidades em propiciar uma educação que transcenda os muros da escola a partir de uma educação crítica pautada em uma perspectiva progressista.

A partir deste momento, deu-se início ao desejo de ser professora, assim, no ano de 2012 surgiu a oportunidade de ingressar no Programa Institucional de Bolsas de Iniciação à Docência (PIBID), com permanência até o ano de 2016, atuando em escolas estaduais da cidade de Dourados - MS. Tendo a possibilidade de desenvolver distintas propostas metodológicas vinculadas ao ensino de Química e articular a Formação Inicial com o contexto da escola pública. Etapa importante no processo formativo, por possibilitar-me compreender que a universidade e a escola constituem-se como espaços formativos de igual significância, e que sua inter-relação possibilita com que a escola se torne protagonista no processo de formação de futuros professores. Além disso, propicia com que os professores mais experientes tornem-se co-formadores de professores.

Ainda no PIBID, foi possível desenvolver atividades pedagógicas pautadas na perspectiva CTS, o que me possibilitou compreender melhor os objetivos da implementação de um currículo pautado nesta perspectiva. Objetivos estes, que vão desde uma alfabetização que relacione aspectos científicos, tecnológicos e sociais até a formação de um cidadão crítico.

Na etapa final da graduação, ao elaborar o Trabalho de Conclusão de Curso (TCC) emergiu a possibilidade de desenvolver uma sequência didática pautada na perspectiva CTS e avaliar suas potencialidades e limitações no processo de ensino e aprendizagem. Desta forma, a proposta foi elaborada ancorada nos Três Momentos Pedagógicos (DELIZOICOV E ANGOTTI, 1991; DELIZOICOV, ANGOTTI e PERNAMBUCO, 2002) abordando o tema plásticos para o ensino e aprendizagem do conteúdo de polímeros. No terceiro momento da sequência didática, foi realizada uma atividade argumentativa, júri simulado, abordando a problemática da proibição das sacolas plásticas. O que possibilitou promover o debate de questões controversas em sala de aula e apresentar aos educando uma situação onde deveriam agir conscientemente realizando uma tomada de decisão que envolvesse questões científicas, tecnológicas, ambientais e sociais.

A partir da aplicação e análise do TCC várias reflexões emergiram e foram retomadas. Reflexões que se iniciaram nos componentes curriculares de Prática de Ensino de Química, momento no qual pude perceber certa dificuldade por parte dos colegas de formação, quando se tratava da articulação entre a tríade CTS, ou em relação a compreensões errôneas sobre o movimento CTS, entendimentos que denotavam crenças em perspectivas tecnocráticas. Por outro lado, também se pôde observar a importância dada pelos acadêmicos à inserção do movimento no contexto educacional, objetivando a formação de cidadãos críticos. Tais reflexões e análises desvelaram-me a seguinte indagação, a qual sua possível resposta ou compreensão ainda está em processo de construção: "O futuro professor durante seu curso de graduação é subsidiado a desenvolver em seus alunos, habilidades defendidas pelo movimento CTS?"

\section{O despertar crítico}

O processo de Formação Inicial possibilitou várias compreensões e reflexões acerca do "ser professor". Primeiramente, o entendimento de que a formação do professor deve ser constante, com um início, porém sem um fim determinado. E a necessidade de que os 
professores busquem subsídios teóricos para transcenderem seus limites de reflexão, pois muitas vezes limitam seu mundo de reflexão e ação à sala de aula. Quando esta limitação é superada ocorre uma abertura de possibilidades variadas de romper com a visão meramente técnica do trabalho docente, abrindo uma pluralidade de possibilidades na busca pela autonomia e emancipação de sua prática pedagógica.

As reflexões, análises e indagações realizadas durante o período de graduação transformaram-se em objeto de pesquisa ao ingressar no Programa de Pós-Graduação em Ensino de Ciências, na Universidade Federal de Mato Grosso do Sul (UFMS) na cidade de Campo Grande - MS, no ano de 2016. Onde atuo na linha de pesquisa de Formação de Professores, mais especificamente à Formação Inicial de Professores articulada ao movimento CTS.

A imersão no mestrado possibilitou o encontro com leituras do teórico crítico Henry Giroux, considerado um dos fundadores da pedagogia Crítica. Os três pilares de sua teoria de política cultural, baseia-se em: Os professores como Intelectuais Transformadores, atuantes na esfera pública, a escola como local público, vista sob uma lente de produção de conhecimento e emancipação dos sujeitos e a crítica aos currículos. A partir das leituras, aflorou-me a necessidade em realizar uma auto-formação e constituição da identidade docente aos moldes do modelo formativo do professor como Intelectual Crítico, proposto por Giroux (1997), por acreditar que sob este viés haja uma melhor formação de um professor que esteja comprometido com transformações e busca pela autonomia no fazer pedagógico.

A ideia de intelectual defendida por Giroux baseia-se numa aproximação mais ampliada da concepção de intelectual defendida por Antonio Gramsci, o qual assinala que os intelectuais conservadores são aqueles que estão a serviço do status quo. Para Gramsci, os intelectuais não seriam apenas homens alfabetizados e transmissores de conhecimentos, mas seriam também mediadores e produtores de ideias. Giroux (1997) apresenta uma compreensão mais profunda e avançada em relação aos intelectuais, onde apresenta a concepção do professor como Intelectual Transformador. Podendo ser compreendido como uma forma de repensar e reestruturar criticamente as ações pedagógicas do docente, objetivando atingir os extramuros da escola, na busca por uma transformação social. Para Giroux (1997), os professores como intelectuais transformadores devem:

\begin{abstract}
(...) fornecer aos estudantes os instrumentos críticos para compreender e desmantelar a racionalização crônica de práticas sociais prejudiciais, e, ao mesmo tempo, apropriar-se do conhecimento e das habilidades que precisam para repensar o projeto de emancipação humana. Em segundo lugar os intelectuais transformadores devem engajar-se ativamente em projetos que os estimulem a abordar seu próprio papel crítico na produção e legitimação das relações sociais. Tais projetos são necessários não apenas para lutar contra os intelectuais conservadores e os múltiplos contextos nos quais os processos de legitimação ocorrem, mas também para ampliar os movimentos teóricos e políticos fora da universidade. Os intelectuais transformadores devem desenvolver e trabalhar com movimentos fora dos contornos limitantes das disciplinas, simpósios e sistemas de recompensa que tornaram-se os únicos referenciais da atividade intelectual. Ainda mais importante, tal projeto amplia a noção de educação e leva a sério a noção de Gramsci de toda a sociedade como uma grande escola (GIROUX, 1997 p. 188).
\end{abstract}

O autor propõe a ideia do professor como intelectual crítico transformador com o objetivo de repensar e analisar a natureza da atividade docente. Desta forma, o professor torna-se um sujeito capaz de inserir-se na esfera pública, utilizando seus conhecimentos para atuar de maneira a propiciar uma transformação tanto de sua prática pedagógica quanto da sociedade. 
Para questionar a função dos intelectuais críticos, Giroux (1997) considera importante enxergar a escola como uma esfera pública, abordando questões sociais, econômicas e culturais diretamente ligados a questões de controle. Em suma os intelectuais enxergam e são enxergados sob uma lente dos interesses políticos e ideológicos que ancoram a natureza da prática pedagógica. Para o autor, os professores devem se tornar intelectuais transformadores se quiserem educar seus estudantes para serem cidadãos ativos e críticos.

Os pressupostos CTS encaminham-se atrelados a várias questões discutidas por Giroux, assim como o modelo formativo de professores como intelectuais transformadores objetivam a formação de cidadãos conscientes e críticos. A abordagem CTS traz como pressupostos a formação do indivíduo para a cidadania, desenvolvendo-lhes valores e habilidades para exercer tal papel com consciência, sendo capaz de realizar uma leitura crítica das adversidades sociais.

Neste momento, realizo uma aproximação do modelo formativo que estava implícito, inconscientemente, em algumas práticas pautadas na abordagem CTS, mais precisamente no desenvolvimento do TCC. Tais abordagens apresentavam em sua essência, bem como em seu discurso traços do modelo formativo de professores como Intelectuais, uma vez que se torna possível identificar alguns critérios apresentados por Giroux (1997). Fato que favoreceu autocompreensão sobre a prática e sobre a formação da identidade docente.

Ainda sobre a prática desenvolvida no TCC, mais precisamente no terceiro momento pedagógico, momento no qual os educandos deveriam fazer uso dos conhecimentos construídos ao longo de todo o processo pedagógico, para aplicá-lo de forma crítica e consciente em uma problemática social. Neste sentido, cabe destacar que nesta etapa foi possível desenvolver discussões de várias naturezas, dentre elas política. Sobre este fato Giroux (1997, p. 163) explicita que é primordial para o professor intelectual transformador “tornar o pedagógico mais político e o político mais pedagógico". Neste sentido, tornar o pedagógico mais político significa inserir a escola na esfera política, buscando uma resposta em torno das relações de poder e opressão, visto que tais discussões propiciam o desvelamento de compreensões acerca das injustiças sociais, políticas, éticas a fim de superálas.

Tornar o político mais pedagógico seria ações realizadas no fazer pedagógico, onde se busca uma aproximação constante com questões que abordam interesses políticos, sociais e econômicos. Porém, tais abordagens devem apresentar um caráter emancipador, vislumbrando a autonomia e transformação social. Para isto os intelectuais devem apresentar uma linguagem que relacione a crítica com a possibilidade, manifestando-se contra as adversidades sociais dentro e fora da escola. Procurando subsídios teóricos para possibilitar aos estudantes a oportunidade de tornarem-se cidadãos capazes de realizar uma leitura crítica do mundo no qual estão inseridos.

\section{Imersão em sala de aula: dificuldades emergentes e perspectivas}

Todas as reflexões e compreensões construídas fizeram-me vislumbrar uma educação justa e igualitária, pautada numa perspectiva progressista, que permita os indivíduos tirarem o manto da alienação e enxergarem o sistema de opressão que os assola. Desta forma, neste ano de 2017, ingressei numa escola estadual na cidade de Campo Grande - MS, como professora de Química, atuando no Ensino Médio. A partir desta imersão desvelaram-se algumas dificuldades e observações, dificuldades ligadas mais especificamente à aplicação de 
atividades pautadas em tendências progressistas, mais especificamente relacionadas ao movimento CTS.

Tais dificuldades, relacionam-se principalmente aos processos políticos pedagógicos vivenciados no espaço escolar, onde as problemáticas sociais, imprescindíveis para a formação de cidadãos segue restrito. Um exemplo disso, é o fato de os currículos de Química, Física e Biologia terem permanecido intocáveis por muitas décadas (AULER, 2011). Como se pode exigir mudanças radicais na educação, participação dos professores em processos decisórios, sendo que o contexto escolar é caracterizado por buscar solucionar os problemas sociais mediante a simples busca de inovações metodológicas? Questionamento já realizado por Auler (2011).

Neste viés compreende-se que sem enfrentar o debate curricular, e sem analisar qual é o papel do ensino de ciências dentro do ensino básico, tudo indica que o campo de trabalho CTS, tende a se transformar em mais um modismo, ou em algo que os professores aderem para deixar as aulas mais interessantes (AULER, 2011). Nesta vertente, sobre o papel da escola em formar cidadãos críticos, o autor comenta os valores da configuração curricular e questiona se a intencionalidade deste currículo é democrática ou tecnocrática. Salientando ainda, que se a escolha for a primeira (democrática), o currículo precisa de mudanças radicais, se for a segunda (tecnocrática) a atual concepção curricular já é pautada neste enfoque.

Em relação a configuração curricular, Giroux (1997) apresenta uma crítica ao currículo oculto, ainda presente nas práticas educacionais mesmo que de forma implícita. Apresenta uma essência meramente tecnocrática, pois parte do objetivo de formar cidadãos conformados sem pensamento crítico. Para superar este obstáculo, o autor, defende a quebra da divisão social do trabalho de quem determina o currículo e de quem o executa. Fato que se encaminha em conjunto com questões discutidas na perspectiva CTS. Essa superação da divisão introduzida no trabalho docente entre concepção e execução, busca desenvolver uma perspectiva crítica em relação ao ensino. Segundo Contreras (2012), para superar este obstáculo é necessário indagar-se sobre o que seria um ensino valioso e por que, e não limitarse apenas a como propiciar um ensino valioso.

A estrutura curricular tecnocrática é considerada como balizadora de alguns encaminhamentos CTS, pois é executada de forma com que a fragmentação disciplinar, o estudo, a análise de temas seja realizada sob a lente das ciências naturais, sem realizar vínculos com outras ciências. Nesta vertente, os alunos analisam os temas sociais numa vertente científico-tecnológica, apenas com a visão embasada nas ciências naturais e possivelmente construirão a compreensão de que os conhecimentos obtidos são suficientemente necessários para resolver os problemas sociais. A tentativa de buscar resolver um problema desvinculando-o das relações sociais em que se estabelece, avaliando-os somente a partir de conhecimentos científico-tecnológicos, significa um retorno à tecnocracia (AULER, 2011).

O autor considera que houve uma defasagem, no contexto brasileiro, no que diz respeito a uma educação para a cidadania, pontuando que o professor passou a exercer uma aproximação com perspectivas tecnocráticas, obstáculo que deve ser superado. Com relação a isto o autor comenta que com o passar do tempo houve uma desprofissionalização do professor, pois este passou a exercer um papel de mero executor de currículos, pois coloca em prática um currículo não neutro, mas marcado por intencionalidades que foram definidos por outros, em âmbitos diferentes do qual será aplicado. Neste viés, o papel do professor acaba sendo o de "cumprir a ementa" e "vencer o conteúdo", mesmo tendo a consciência da importância pela busca de novas metodologias. Auler (2011, p. 91), compara o professor com Charles Chaplin do filme "Tempos Modernos": "Assim como este, executa diariamente, de 
forma mecânica, tarefas repetitivas, concebidas por outros, o professor, ano após ano, deve executar, cumprir currículos, intencionalidades definidas por outros".

Este fato, marca a racionalidade técnica explícita nas práticas pedagógicas, e para superar tal problemática, Contreras (2012) considera importante, aumentar o compromisso com o valor da educação. Desta forma, cabe ao professor questionar-se que tipo de educação está sendo construída? Que espécie de indivíduos pretende-se formar a partir da prática pedagógica? Mas para realizar tais questionamentos há a necessidade de posicionar-se como intelectual crítico, buscando romper com as adversidades emergentes do sistema.

A questão curricular discutida nos encaminhamentos CTS, considera que o conjunto de conhecimentos trabalhados necessita de um redimensionamento, pois deve contribuir, através da educação, para a democratização de processos decisórios implicando considerações políticas, econômicas e sociais. Para atender a esta concepção curricular, devem ser inseridos no debate temas sociais, que apresentem questões políticas e econômicas, para que desta forma, possa-se obter a partir da formação de um cidadão encaminhamentos/ações que propiciem a resolução do âmbito social.

Como foi visto, há diversos obstáculos para a inserção do enfoque CTS no ensino, e fica explícito que uma educação com este enfoque possibilita aos alunos uma compreensão mais profunda do universo científico com o cotidiano, pois o uso de temas evidenciam as inter-relações entre aspectos relacionados à CTS, além de propiciar condições para o desenvolvimento da tomada de decisões pelos educandos.

\section{Busca por um continuum formativo}

Após a imersão no contexto escolar, atuando como professora foi possível notar que um dos problemas centrais do sistema educacional se encontra no fato de que habilidades de argumentação e tomada de decisão sobre questões comuns a sociedade, que deveriam ser aprendidos na escola muitas vezes não são desenvolvidos, nem mesmo no ensino superior (CASSIANI e LINSINGEN, 2009). Este obstáculo desvela a necessidade de realizar ações em todos os níveis de ensino, para que desta forma se possa propiciar uma formação que atenda a todas as necessidades para formar um cidadão crítico.

Neste sentido, o movimento CTS defende a necessidade de despertar atitudes como o senso crítico a capacidade de tomada de decisões conscientes acerca de problemas sociais, possibilitando a formação cidadãos. Sobre a abordagem CTS, cabe salientar a notoriedade da aplicação desta perspectiva dentro de sala de aula, e porque não, implementar nos currículos de ensino médio, porém esta ação depende de uma formação inicial e continuada de professores. Desta forma, em harmonia com as explicitações de Santos e Mortimer (2002), os quais assinalam que sem uma compreensão do papel social do ensino de ciências, por parte dos professores, se pode incorrer no erro de apresentar os conteúdos científicos com pitadas de aplicações na sociedade, destacamos a necessidade de articular o conteúdo de ciências com questões relacionadas à tríade CTS, pois com a ausência desta contextualização se torna difícil a formação para a cidadania.

Ademais, sinalizamos que quando o professor compreende que seu processo formativo deve ser contínuo, com um início, porém sem um fim pré-determinado, articulando saber específico ao saber pedagógico, buscando subsídios teóricos na busca pela sua autonomia profissional e emancipação de sua prática pedagógica, pode-se romper com as práticas de reprodução. Alguns autores (PIMENTA, 1996; ZEICHNER, 1993; PERRENOUD, 1999; BOURDIE, 1998, 2004 e ABRANTES, 2011) consideram que as teorias de reprodução 
explicam o fracasso escolar demonstrando sua reprodução, porém uma reprodução no âmbito das desigualdades sociais. Logo, não são suficientes para compreender a produção das desigualdades do contexto escolar.

Neste viés, voltamos a discussão do professor como intelectual transformador, sinalizando suas potencialidades nos processos formativos, fato apresentado por alguns autores (QUEIRÓS, 2012; OLIVEIRA e QUEIROZ, 2016). Haja visto que este oferece subsídios teóricos para que o professor atue de forma a destacar a luta por uma sociedade mais justa e igualitária, bem como aborda a possibilidade de os docentes compreenderem as potencialidades da emancipação obtida a partir de uma análise crítica das ações pedagógicas. Acerca da formação de professores, Nascimento, Fernandes e Mendonça (2010) julgam necessário que esta, seja considerada sob uma perspectiva de transformação. Desta forma, torna-se possível analisar o contexto e o processo da prática docente como meio na busca por novas possibilidades que superem as deformações ainda vigentes no processo educacional, objetivando potencializar a compreensão crítica do mundo.

Esta ação possibilita com que os alunos consigam, em coletivo, superar a luta contra as impossibilidades de um sistema marcado por intencionalidades, que não se preocupa em ouvir as vozes dos que estão inseridos de forma majoritária no sistema.

\section{REFERÊNCIAS}

ABRANTES, P. Revisitando a teoria da reprodução: debate teórico e aplicações ao caso português. Análise Social, v. XLVI, n. 199, p. 261-281, 2011.

AULER, D. Novos caminhos para a educação CTS: ampliando a participação. In: SANTOS, W. L. P; AULER. D. (orgs). CTS e educação científica: desafios, tendências e resultados de pesquisa. 1. Ed. Brasília: UNB, 2011.

BOURDIEU, P. A Escola conservadora: as desigualdades frente à escola e à cultura. In: NOGUEIRA, M. A.; CATANI, A. (orgs). Escritos de educação. Petrópolis, Vozes, 1998.

BOURDIEU, P. O poder simbólico. Tradução Fernando Tomaz, 7. ed. Rio de Janeiro: Bertrand Brasil, 2004.

CASSIANI, S.; LINSINGEN, I. V. Formação inicial de professores de Ciências: perspectiva discursiva na educação CTS. Educar, n. 34, p. 127-147, 2009.

CONTRERAS, J. A autonomia de professores. São Paulo: Cortez, 2012.

DELIZOICOV. D; ANGOTTI. J. A. Metodologia do ensino de ciências. São Paulo: Cortez, 1991.

DELIZOICOV. D; ANGOTTI, J. A.; PERNAMBUCO, M. M. Ensino de Ciências: fundamentos e métodos. São Paulo: Cortez, 2002.

GIROUX, H. A. Os professores como intelectuais: rumo a uma pedagogia crítica da aprendizagem. Porto Alegre: Artmed, 1997.

NASCIMENTO, F; FERNANDES, H. L.; MENDONÇA, V. M. o ensino de ciências no Brasil: história, formação de professores e desafios atuais. Revista HISTEDBR On-line, n. 39, p. 225-249, 2010.

OLIVEIRA, R. D. V. L.; QUEIROZ, G. R. P. C. A formação do professor como intelectual transformador e os fios que a compõem: uma análise a partir da formação inicial de uma 
professora de Química. Revista Brasileira de Pesquisa em Educação em Ciências, v, 16, n. 2, p. 339-360, 2016.

PERRENOUD, P. Profissionalização do professor e desenvolvimento de ciclos de aprendizagem. Tradução Neide Luzia de Rezende. Cadernos de pesquisa, n. 108, 1999.

PIMENTA, S. G. Formação de professores: saberes da docência e identidade do professor. Revista da Faculdade de Educação, USP, v. 1. n. 1, p.72-89, jul/dez.1996.

QUEIRÓS, W. P. A articulação das culturas humanística e científica por meio do estudo histórico-sociocultural dos trabalhos de James Prescott Joule: contribuições para a formação de professores universitários em uma perspectiva transformadora. Tese (Doutorado) Universidade Estadual Paulista. Faculdade de Ciências, Bauru, 2012.

SANTOS, W. L. P; MORTIMER E. F. Uma análise dos pressupostos teóricos da abordagem C-T-S (Ciência - Tecnologia - Sociedade) no contexto da educação brasileira, Ensaio: pesquisa em educação em ciências, v.2 n. 2, p.1-23,. dez. 2002.

ZEICHNER, K. Formação reflexiva de professores. Lisboa: Educa, 1993. 